\title{
Orexin in Rostral Hotspot of Nucleus Accumbens Enhances Sucrose 'Liking' and Intake but Scopolamine in Caudal Shell Shifts 'Liking' Toward 'Disgust' and 'Fear'
}

\author{
Daniel C Castro*,', Rachel A Terry' and Kent C Berridge' \\ 'Department of Psychology, University of Michigan, Ann Arbor, Michigan, USA
}

\begin{abstract}
The nucleus accumbens (NAc) contains a hedonic hotspot in the rostral half of medial shell, where opioid agonist microinjections are known to enhance positive hedonic orofacial reactions to the taste of sucrose ('liking' reactions). Within NAc shell, orexin/hypocretin also has been reported to stimulate food intake and is implicated in reward, whereas blockade of muscarinic acetylcholine receptors by scopolamine suppresses intake and may have anti-reward effects. Here, we show that NAc microinjection of orexin-A in medial shell amplifies the hedonic impact of sucrose taste, but only within the same anatomically rostral site, identical to the opioid hotspot. By comparison, at all sites throughout medial shell, orexin microinjections stimulated 'wanting' to eat, as reflected by increases in intake of palatable sweet chocolates. At NAc shell sites outside the hotspot, orexin selectively enhanced 'wanting' to eat without enhancing sweetness 'liking' reactions. In contrast, microinjections of the antagonist scopolamine at all sites in NAc shell suppressed sucrose 'liking' reactions as well as suppressing intake of palatable food. Conversely, scopolamine increased aversive 'disgust' reactions elicited by bitter quinine at all NAc shell sites. Finally, scopolamine microinjections localized to the caudal half of medial shell additionally generated a fearrelated anti-predator reaction of defensive treading and burying directed toward the corners of the transparent chamber. Together, these results confirm a rostral hotspot in NAc medial shell as a unique site for orexin induction of hedonic 'liking' enhancement, similar to opioid enhancement. They also reveal distinct roles for orexin and acetylcholine signals in NAc shell for hedonic reactions and motivated behaviors.
\end{abstract}

Neuropsychopharmacology (2016) 4I, 2 I0I-2I I I; do: I0.1038/npp.20 I6.10; published online I0 February 2016

\section{INTRODUCTION}

Pleasure 'liking', or hedonic impact, is a fundamental aspect of sensory reward, and pathological dysfunction of hedonic brain circuitry may contribute to addiction, mood disorders, eating disorders, and obesity. To better understand and map the neural mechanisms underlying hedonic impact, several affective neuroscience studies have used the taste reactivity test to measure orofacial 'liking' reactions to sweet tastes (Berridge and Kringelbach, 2015). These affective facial expressions to taste are homologous in human infants, nonhuman primates, and even rodents (Berridge, 2000; Steiner et al, 2001), and hedonic brain mechanisms can be mapped by their ability to cause changes in such 'liking' reactions.

One example of this hedonic localization involves the nucleus accumbens (NAc), which contains a roughly cubic millimeter-sized 'hedonic hotspot' in the rostral half of medial shell in rats. In that rostral hotspot of NAc shell opioid agonist microinjections can double or triple the number of positive hedonic orofacial reactions (ie, 'liking'

\footnotetext{
*Correspondence: DC Castro, Department of Psychology, University of Michigan, 530 Church Street, Ann Arbor, MI 48109, USA, Tel: + I 4256473890, E-mail: castrod@umich.edu

Received 17 August 2015; revised 6 November 2015; accepted 25 November 2015; accepted article preview online 20 January 2016
}

reactions) elicited by the taste of sucrose (Castro and Berridge, 2014; Pecina and Berridge, 2005). Conversely, in caudal shell, agonist microinjections reveal a 'hedonic coldspot', where opioid stimulation suppresses sucrose hedonic impact (Castro and Berridge, 2014; Pecina and Berridge, 2005). By contrast to the localized hotspot for sweetness 'liking', mu-opioid stimulations increase motivation to eat much more widely and homogeneously throughout the entire NAc shell (and in related structures), measured as increases in cue-triggered 'wanting' to obtain food rewards (eg, in instrumental breakpoint and pavlovian-instrumental transfer tests), as well as in food consumption (Castro and Berridge, 2014; Covelo et al, 2014; Maldonado-Irizarry et al, 1995; Pecina and Berridge, 2005; Pecina and Berridge, 2013; Smith and Berridge, 2005; Smith et al, 2011; Zhang and Kelley, 2000).

Other neurotransmitter systems in NAc also modulate food consumption, motivation, and hedonic impact of food rewards including, endocannabinoids, and amino acids (Maldonado-Irizarry et al, 1995; Shinohara et al, 2009; Soria-Gomez et al, 2007), some of which might interact with opioid signals in NAc shell (Faure et al, 2010; Mahler et al, 2007). Here we extended our analyses to orexin and acetylcholine $(\mathrm{ACh})$ systems in NAc that modulate intake 
and food-motivated behaviors (Pratt and Kelley, 2004; Pratt et al, 2007; Thorpe and Kotz, 2005).

Orexin-A (hypocretin) is a hypothalamic peptide implicated in reward (Barson et al, 2015; Berthoud and Munzberg, 2011; Harris et al, 2005; Sharf et al, 2010), as well as in arousal (Espana et al, 2003; Rolls et al, 2011; Sutcliffe and de Lecea, 2002). Orexin can also amplify hedonic 'liking' reactions to sucrose taste, comparably to mu-opioid stimulation, if microinjected into another opioid hedonic hotspot located in posterior ventral pallidum (Ho and Berridge, 2013; Smith and Berridge, 2005). Anatomically, hypothalamic orexin neurons send projections throughout the brain, including to NAc shell (but not core) (Baldo et al, 2003; Peyron et al, 1998). This projection pattern raises the question of whether orexin might also enhance hedonic reactions within the NAc-opioid hotspot, similarly to the ventral pallidum hotspot. Orexin-induced increases in food intake can be prevented by opioid blockade (Sweet et al, 2004), and orexin in NAc can modulate phasic dopamine release, which may be related to incentive motivation to eat (Patyal et al, 2012; Thorpe and Kotz, 2005).

$\mathrm{ACh}$ in NAc has also been implicated in food reward (Perry et al, 2009; Perry et al, 2014; Pratt et al, 2007), and this role has been suggested to involve interactions with NAcopioid and dopamine systems (Perry et al, 2014; Pratt and Kelley, 2005; Stouffer et al, 2015). Although early studies suggested that $\mathrm{ACh}$ might primarily suppress intake via satiety or aversion, since ACh levels rise gradually during food intake and after exposure to aversive tastes (Avena et al, 2008; Mark et al, 1992; Mark et al, 1995), more recent studies have implicated endogenous ACh in NAc and striatum in the appetitive motivation for food rewards (Perry et al, 2009; Perry et al, 2014; Pratt et al, 2007). For example, blockade of endogenous $\mathrm{ACh}$ in NAc by microinjections of the muscarinic antagonist scopolamine suppresses food intake, and establishes learned taste or place avoidances. Further, the ability of mu-opioid agonist microinjections in NAc to stimulate food intake is also blocked by simultaneous blockade of ACh muscarinic receptors (Perry et al, 2014), which alters striatal preproenkephalin mRNA levels (Pratt and Kelley, 2005), suggesting the possibility of an AChopioid interaction in NAc in food reward. Therefore, it is of interest to examine the roles of endogenous ACh in NAc on the hedonic impact of palatable foods as well as on the motivation to eat.

Here we compared orexin-A microinjections and scopolamine microinjections at various sites in NAc medial shell for their effects on (1) intake of a palatable sweet food (chocolate candies), (2) positive 'liking' taste reactions elicited by oral infusions of sucrose solution, and (3) negative 'disgust' reactions elicited by infusions of bitter quinine solution. Our results suggest the existence of a localized hedonic hotspot for orexin enhancement of hedonic impact in rostral NAc shell (similar to opioid enhancement). The results also suggest a more widespread anatomical substrate, distributed throughout entire NAc shell, for orexin stimulation of food intake. A similar distributed NAc network is suggested for endogenous ACh contributions to positive hedonic impact and to food intake, with an additional motivational role for the caudal half of NAc, where ACh blockade additionally releases a fear-related anti-predator reaction of defensive treading.

\section{METHODS}

\section{Subjects}

Sprague Dawley rats ( 3 months old) weighing $250-450 \mathrm{~g}$ at surgery (total $n=25$ (female $=14$, weight 250-300 g; male $=11$, weight $350-450 \mathrm{~g})$ ) were housed in same-sex pairs at $\sim 21^{\circ} \mathrm{C}$ on a reverse $12 \mathrm{~h}$ light/dark cycle and used in the microinjection-behavior tests. An additional, separate group of four rats were used solely for histological analysis of Fos plume diameters (to assess diameters of a 'first drug microinjection'). All rats had ad libitum access to food and water in their home cage. All experimental procedures were followed and approved by the University of Michigan Committee on the Use and Care of Animals.

\section{Surgery}

Rats were implanted with oral and cranial cannulas as described previously (Castro and Berridge, 2014). Briefly, bilateral oral cannulas entered the mouth in the upper cheek pouch lateral to the first maxillary molar, ascended beneath the zygomatic arch, and then exited through the skin at the dorsal head cap (Grill and Norgren, 1978). In the same surgery, permanent microinjection guide cannulas were bilaterally implanted. Bilateral coordinates were identical for a given rat, but sites were staggered across rats to fill the entire NAc medial shell for the group as a whole. Rostral shell placements $(n=15)$ averaged around +3.1 anteroposterior (AP) from Bregma, bilateral $\pm 0.9 \mathrm{~mm}$ mediolateral (ML), and $-5.7 \mathrm{~mm}$ dorsoventral (DV). Caudal placements $(n=10)$ averaged between +2.6 and $+2.8 \mathrm{~mm} \mathrm{AP}, \pm 0.9 \mathrm{~mm}$ $\mathrm{ML}$, and -5.7 and $-6.0 \mathrm{~mm} \mathrm{DV}$. After surgery, each rat received subcutaneous injections of carprofen $\left(5 \mathrm{mg} \mathrm{kg}^{-1}\right)$ for pain relief, as well as topical antibiotic around the perimeter of the head cap. Rats received another dose of carprofen $24 \mathrm{~h}$ later, and reapplication of topical antibiotic, and were allowed to recover for 1 week before behavioral testing began.

\section{Drug Microinjections}

Rats were hand-held in the lap of the experimenter during NAc microinjections. Polyethylene PE-20 tubing was connected to a stainless steel microinjection cannula injector, which had a tip ( $16 \mathrm{~mm}, 29$ gauge) extending $2 \mathrm{~mm}$ beyond the ventral end of guide cannulas to reach the NAc target site. On test days, solutions were brought to room temperature $\left(\sim 21^{\circ} \mathrm{C}\right)$ before bilateral microinjection. Drugs were dissolved in a vehicle of artificial cerebrospinal fluid (ACSF). Microinjection solutions contained one of the following (drug order was counter-balanced across rats used for behavioral tests): (1) orexin-A, a hypothalamic neuropeptide $(500$ pmol per $0.2 \mu \mathrm{l}$; also known as hypocretin-1); (2) scopolamine, a muscarinic antagonist $(10 \mu \mathrm{g}$ per $0.5 \mu \mathrm{l})$; or (3) ACSF vehicle alone in a volume of $0.2 \mu \mathrm{l}$ per side (vehicle control condition). Drug doses and volumes were chosen based on most behaviorally effective dose/volume from Thorpe and Kotz (2005) for orexin, and from Pratt et al (2007) for scopolamine. Drugs were prepared fresh at the beginning of each test group, and then either frozen (ACSF, orexin) or refrigerated (scopolamine) in solution for testing 
later that week. Each $0.2 \mu \mathrm{l}$ microinjection was delivered during a $1 \mathrm{~min}$ period at a speed of $0.2 \mu \mathrm{lmin} \mathrm{m}^{-1}$ by syringe pump. After bilateral microinjections, injectors were left in place for $1 \mathrm{~min}$ to allow for drug diffusion, after which obturators were replaced and rats were immediately placed in the taste reactivity testing chamber. Each rat received bilateral microinjections of only one drug or vehicle solution per test day.

\section{Taste Reactivity Testing}

Before testing, rats were each extensively handled to familiarize them with experimenters. They were then habituated to the test chamber for $25 \mathrm{~min}$ for 4 consecutive days, and received a mock injection of vehicle ACSF on the final day of habituation.

The taste reactivity test (Grill and Norgren, 1978; Steiner, 1973; Steiner et al, 2001) was used to measure a rat's affective orofacial reactions to either a sucrose solution (1.0\%, $0.029 \mathrm{M})$ or a quinine solution $\left(3 \times 10^{-3} \mathrm{M}\right)$. A $1 \mathrm{ml}$ volume of each solution was infused over a $1 \mathrm{~min}$ period via syringe pump through plastic tubing connected to the rat's oral cannula (PE-50 connected to a PE-10 delivery nozzle). On each test day, the sucrose solution was infused 25 min after a NAc microinjection of vehicle, orexin, or scopolamine. After a 5 min delay, a 1-min infusion of quinine followed for a second taste reactivity test. This order was used because if quinine were first, the bitterness disgust could easily carry over and suppress positive reactions to subsequent sucrose. However, sweet tastes do not appear to disrupt negative 'disgust' reactions to subsequent bitterness in our experience, and so a sucrose-quinine order of testing was used (Pecina and Berridge, 2005). Orofacial taste reactivity responses to both solutions were video recorded via closeup lens for subsequent slow-motion video-analysis as described previously (Castro and Berridge, 2014).

Males and females were run in separate same-sex cohorts on different days to prevent any lingering opposite-sex odors from affecting behavior. Test chambers were cleaned with soap and water at the end of each test day. Male and female Fos groups were also run separately for microinjections and perfusions to prevent any pheromone modulation of neuronal gene expression.

\section{Food Intake Testing}

A $1 \mathrm{~h}$ free intake test was administered immediately following the taste reactivity test on each test day. Rats previously had been habituated to the food intake chamber during the 4 habituation days. Each intake chamber $(23 \times 20 \times 45 \mathrm{~cm})$ contained a large pile of palatable chocolate (M\&Ms), and an ad libitum water spout, and the floor was covered with $1 \mathrm{~cm}$ depth of corncob bedding. The amount of M\&M candies ( $20 \mathrm{~g})$ was weighed before and after testing to calculate amount of food intake, and water consumption was measured. All behavior was video recorded and later scored for eating behavior (duration in seconds), water drinking behavior (in seconds), grooming behavior (in seconds), treading (in seconds), and for number of bouts of food sniffs, food carrying or burying, cage crosses, and rears.

\section{Histology and Fos-like Protein Immunohistochemistry}

After the last day of behavioral testing, rats were deeply anesthetized with an overdose of sodium pentobarbital. Rats were decapitated and the brains were extracted and fixed in $10 \%$ paraformaldehyde solution for 1-2 days followed by a $25 \%$ sucrose solution in $0.1 \mathrm{M} \mathrm{NaPb}$ for 2-3 days before slicing. $60-\mu \mathrm{m}$ slices through the NAc were taken from each rat on a cryostat, mounted, dried, and stained with cresyl violet. Microinjection center was determined for each bilateral injection site and slides were compared with the stereotaxic atlas (Paxinos and Watson, 2007) to determine placement in the NAc.

Fos immunohistochemistry and plume analysis was performed on four naive rats, so that plume diameters would be maximal, and not shrunken due to gliosis/necrosis from any previous microinjection. Fos analysis was also performed on 10 rats from the microinjection-behavior test groups for comparison (as previously described by Castro and Berridge (2014)). In brief, rats received a microinjection of vehicle, orexin, or scopolamine $90 \mathrm{~min}$ before being killed and perfused. Brains were extracted, left in $4 \%$ paraformaldehyde for $24 \mathrm{~h}$, and switched to a $25 \%$ sucrose solution the following day. Forty $\mu \mathrm{m}$ thick slices were taken on a cryostat through NAc and processed for Fos-like immunoreactivity using normal donkey serum, goat anti-c-fos (Santa Cruz Biotechnology), and donkey antigoat AlexaFluor 488 (Invitrogen). Sections were mounted, air-dried, and coverslipped with ProLong Gold antifade reagent (Invitrogen).

The mapping of site effects for localization of function was constructed in a sagittal plane to allow representation of the entire rostrocaudal and DV extent of NAc medial shell. Symbols were color coded to express the intensity of taste reactivity or food intake behaviors relative to vehicle. Symbols were sized to match the mean maximal diameter of measured Fos plumes. For statistical contrasts, sites between +2.4 and $+1.5 \mathrm{~mm}$ anterior to Bregma were classified as in rostral half of medial shell (ie, rostral to +1.5 ), and sites between +0.4 and $+1.5 \mathrm{~mm}$ were classified as caudal placements (ie, caudal to +1.5 ).

\section{Statistical Analysis}

Statistical analyses were performed using non-parametric tests for within-subject (Friedman, Wilcoxon) and betweensubject comparisons, and effect sizes and confidence intervals were included when appropriate.

\section{RESULTS}

\section{Fos Plumes}

Without drug, vehicle microinjections by themselves mildly increased local Fos by $125 \%$ over levels found in normal NAc tissue of intact brains, within a $0.38 \mathrm{~mm}$ radius of the injector tip (volume $=0.23 \mathrm{~mm}^{3}$ ). Orexin microinjections produced more intense local inner plumes of Fos elevation, which were $>200 \%$ over those vehicle levels as well as over normal tissue levels (radius $=0.14 \mathrm{~mm}$ for $>200 \%$ over vehicle levels; volume $\left.=0.011 \mathrm{~mm}^{3}\right)$. This inner orexin-induced plume was surrounded by a larger plume of moderate 
$>125 \%$ Fos elevation over vehicle levels (radius $=0.24 \mathrm{~mm}$; volume $=0.058 \mathrm{~mm}^{3}$ ), and that outer plume radius was similar to the orexin radius of $200 \%$ elevation over normal tissue levels (radius $=0.26 \mathrm{~mm}$; volume $=0.074 \mathrm{~mm}^{3}$ ). Thus, the total diameter of a Fos plume induced by orexin was $\sim 0.5 \mathrm{~mm}$, which was assigned to be the size of orexin site symbols in functional maps. Scopolamine microinjections produced a less intense inner excitatory Fos plume of $>125 \%$ elevation over vehicle with a (radius $=0.20 \mathrm{~mm}$; volume $=0.034 \mathrm{~mm}^{3}$ ), surrounded by a larger inhibitory anti-plume where Fos expression was actually decreased by $25 \%$ below vehicle levels (radius $=0.23 \mathrm{~mm}$; volume $=$ $0.051 \mathrm{~mm}^{3}$ ). This total diameter of $0.46 \mathrm{~mm}$ was assigned to scopolamine symbols in functional maps. The scopolamineinduced halo of inhibition could reflect either lateral interactions between medium spiny neurons, or opposing drug effects at different drug concentrations as the drug diffuses away from the microinjection center. Collectively, these data indicate that even vehicle microinjections produce a local plateau of mild elevation in Fos immunoreactivity, while scopolamine adds a $125 \%$ greater inner peak plus an outer surround inhibition, and orexin produces an even greater $200 \%$ inner peak with a broader base of $125 \%$ local elevation.

\section{No Sex Differences in Drug Effects}

Females and males were first compared for behavioral sex differences in taste reactivity or food intake measures after vehicle or drug microinjections. At baseline, female rats emitted more taste-elicited orofacial reactions than males after vehicle microinjections (vehicle, $\chi^{2}=6.945, p=0.008$; sucrose-positive reactions, $Z=2.635, p=0.008$; sucrosenegative reactions, $Z=2.70, p=0.007$; and quinine-negative reactions: $Z=2.097, p=0.035$ ). These results are consistent with earlier reports that females generally display higher orofacial reactivity to taste palatability than males (Clarke and Ossenkopp, 1998; Flynn et al, 1993). Despite these baseline differences, males and females did not differ for orexin/scopolamine drug effects, expressed as percent change from vehicle baselines in taste reactivity (orexin, $\chi^{2}=2.865, p=0.091 ;$ scopolamine, $\left.\chi^{2}=1.277, p=0.258\right)$, suggesting that the drugs similarly altered palatability in females and males. Since males and females did not differ in drug effects on hedonic impact, their data was pooled together for subsequent analyses of drug effects expressed as percent change from vehicle baselines. For food intake, no sex differences were observed in vehicle baseline, or in orexin or scopolamine conditions (vehicle, $Z=0.408, p=0.689$; orexin, $Z=4.633, p=0.110$; and scopolamine, $Z=0.245$, $p=0.810)$. Female and male data for food intake were therefore similarly pooled in subsequent analyses. All main effects described below applied to both sexes, unless noted.

\section{Orexin in Rostral Shell Enhances Hedonic Reactions to Sucrose}

Orexin-A microinjections altered orofacial reactions to sucrose, but only at particular rostrocaudal locations in NAc shell (Kruskal-Wallis, rostral $v s$ caudal sites, $\chi^{2}=5.867$, $p=0.015$ ) (Figure 1). At sites located in the rostral half of medial shell of NAc (ie, overlapping with the previously identified opioid hotspot), orexin microinjection caused a $200-400 \%$ increase in the number of positive hedonic reactions elicited by sucrose taste, compared with vehicle control trials for the same rats (Friedman's ANOVA, $\chi^{2}=17.868, p=0.000132$; Wilcoxon, $Z=-2.559, p=0.010$; Rostral NAc, $\chi^{2}=21.571, p=0.000021 ; Z=-3.413, p=0.001$; $r=0.88$; and $96.5 \% \mathrm{CI}(3,6))$. By contrast, orexin stimulation in caudal NAc shell produced no change in hedonic reactions to sucrose $\left(\chi^{2}=6.914, p=0.032 ; Z=-1.193, p=0.233\right)$. Thus, hedonic enhancements appeared to be restricted to a subregion in the rostral half of medial shell.

Within the rostral half of medial shell, the magnitude of enhancement of sucrose hedonic impact did not differ between dorsal and ventral portions of the rostral zone (entire shell: $\chi^{2}=0.153, \quad p=0.395$; rostral, $\chi^{2}=1.233$, $p=0.267$ ) (Figure 2). However, our ventral sites in this study did not extend into the most ventral $25 \%(\sim 0.5 \mathrm{~mm})$ portion of rostral shell, making it difficult to know if the orexin hotspot filled the entire rostral half of medial shell or merely the dorsal two-thirds of the rostral half. The latter would be most similar to the original map of opioid hotspot (Pecina and Berridge, 2005). Microinjections of orexin in rostral shell did not alter aversive reactions to either sucrose (which always remained near zero $(Z=-0.813, p=0.416)$ ) or to quinine $(Z=-1.630, p=0.103)$. Similarly, orexin microinjections even at rostral sites failed to alter positive hedonic reactions to quinine (which always remained near zero; $Z=-1.414, p=0.157)$.

Using the $0.5 \mathrm{~mm}$-diameter outer Fos plume measurements to estimate extent of drug-impact spread from effective sites, the rostral boundary of the orexin hedonic hotspot extended to where the corpus callosum joins hemispheres (AP +2.52). It is difficult to know if the boundary extends any more anteriorly, because we did not have any sites further rostral than $+2.28 \mathrm{~mm}$ to Bregma. The caudal boundary was well mapped by posterior silent sites, which revealed the orexin hotspot extended caudally to the edge of the paralamboid septal nucleus $(\mathrm{AP}+1.44)$, beyond which orexin sites no longer had hedonic effects. The medial boundary reached approximately the lateral septum dorsally, the rostral ventral pallidum caudally, and the islands of Calleja at some mid-AP sites ventrally ( $\mathrm{ML} \pm 0.51)$. The lateral boundary was always the border between NAc shell and core $(\mathrm{ML} \pm 1.44)$. The hotspot extended dorsally to the lateral septum and lateral ventricle (DV -6.06), and ventrally at least to the bottom one-fourth of medial shell (DV - 8.34).

We calculated the volume of the orexin enhancement hotspot to be $\sim 1.34 \mathrm{~mm}^{3}$ using the inner $200 \%$ Fos plumes volumes. This volume is similar to the opioid hotspot previously reported in the same rostrodorsal region of medial shell (Castro and Berridge, 2014; Pecina and Berridge, 2005), though slightly larger (112\% compared with opioid hotspot). This similarity suggests that orexin and opioid signals share nearly the same anatomical hotspot within medial shell for hedonic enhancement of sucrose 'liking' reactions.

\section{Orexin Enhances Food Intake Throughout Entire Shell}

Orexin microinjection at virtually all sites throughout the entire medial shell of NAc increased palatable food intake by $\sim 150 \%$ (chocolate M\&M candies) compared with vehicle trials in the same rats $\left(\chi^{2}=30.333, p=0.0000001 ; Z=-2.001\right.$, 

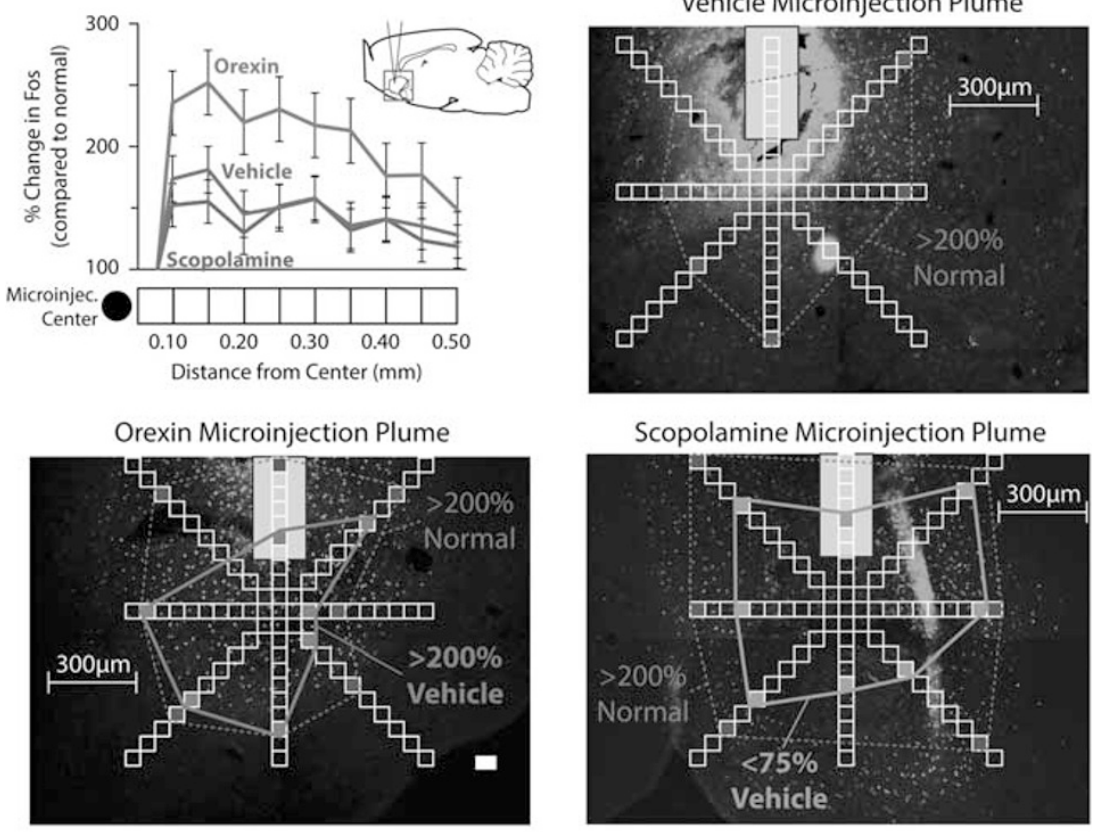

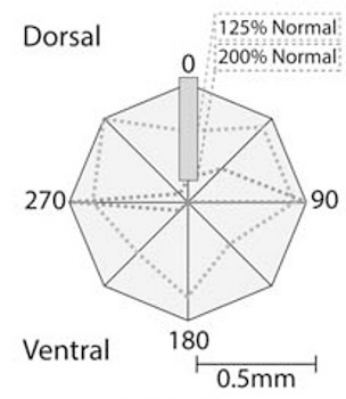

$\overline{\mathrm{x}}$ Vehicle Plume

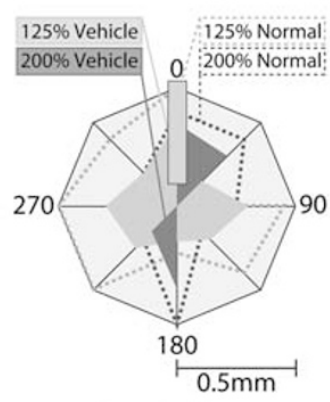

$\overline{\mathrm{x}}$ Orexin Plume

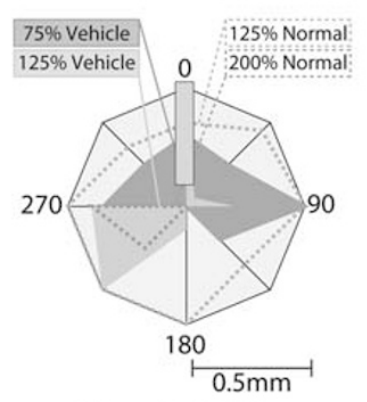

$\overline{\mathrm{X}}$ Scopolamine Plume

Figure I Orexin and scopolamine drug microinjection Fos plumes. Local Fos expression surrounding vehicle, orexin, or scopolamine microinjections (top-left). Photomicrographs show Fos expression after vehicle (top-right), orexin (middle-left), or scopolamine (middle-right) microinjections in NAc shell for individual rats, compared with levels in normal NAc tissue. Plumes 200\% elevated over normal tissue levels are outlined with a dashed red line, whereas 200\% elevations over slightly higher vehicle microinjection levels are outlined by red solid lines (blue solid lines $=25 \%$ decrease below vehicle-induced levels). Mean plume radius shown for vehicle (bottom-left), orexin (bottom-middle), and scopolamine (bottom-right) microinjections relative to normal control brains (dashed lines) or vehicle brains (filled lines). NAc, nucleus accumbens. A full color version of this figure is available at the Neuropsychopharmacology journal online.

$p=0.045 ; r=0.28 ; 95.7 \%$ CI $(2.8,4.9))$. Sites in the caudal half of shell were as effective as sites in the rostral half at supporting increases in eating (caudal mean $=7.41$, S.E. $=1.09$; rostral mean $=6.69$, S.E. $=0.93 ; \chi^{2}=0.077, p=0.781$ ). Similarly, there was no difference between dorsal $v s$ ventral sites in medial shell for orexin-induced increases in intake $\left(\chi^{2}=0.013, p=0.909\right)$. Thus, orexin increased eating equally throughout virtually the entire medial shell (Figure 4), consistent with previous reports by Thorpe and Kotz (2005). Widespread distribution of sites throughout NAc for orexin-induced increase in intake is also similar to mu-opioid stimulation of eating throughout the entire NAc shell (despite the localization of hedonic hotspots for both in rostral shell, and not caudal shell) (Castro and Berridge, 2014; Zhang and Kelley, 2000).

\section{Scopolamine at All Sites Suppresses Sucrose Hedonic Impact and Elevates Quinine 'Disgust'}

Microinjections of the muscarinic ACh antagonist scopolamine in medial shell suppressed positive hedonic orofacial reactions elicited by the taste of sucrose by $\sim 30 \%$ below vehicle control levels in the same rats (Figure 2) $\left(\chi^{2}=17.868\right.$, $p=0.000132 ; \quad Z=-2.585, \quad p=0.010 ; \quad r=0.37 ; 95.7 \% \quad$ CI $(-3,0))$. Essentially all sites throughout medial shell generated similar suppressions of 'liking' reactions to sucrose, with no difference in magnitude between rostral $v s$ caudal sites $\left(\chi^{2}=0.946, p=0.397\right)$, or dorsal $v s$ ventral sites $\left(\chi^{2}=2.432, p=0.119\right)$. However, despite suppressing hedonic reactions to sucrose, scopolamine microinjections never actually induced aversive gapes or other 'disgust' reactions to sucrose $\left(\chi^{2}=4.617, p=0.099 ; Z=-1.451, p=0.147\right)$.

By contrast, aversive 'disgust' reactions to bitter quinine, which were already robust on control trials after vehicle microinjections, were nearly doubled in number after scopolamine microinjections at essentially all sites throughout medial shell $\left(\chi^{2}=21.273, p=0.000024 ; Z=-3.311\right.$, $p=0.001 ; r=0.47 ; 95.7 \%$ CI $(8,23))$. The elevation of quinine 'disgust' reactions was equally robust at sites, whether in rostral halves or caudal halves of medial shell $\left(\chi^{2}=1.294, p=0.255\right)$. Positive hedonic reactions to quinine, 

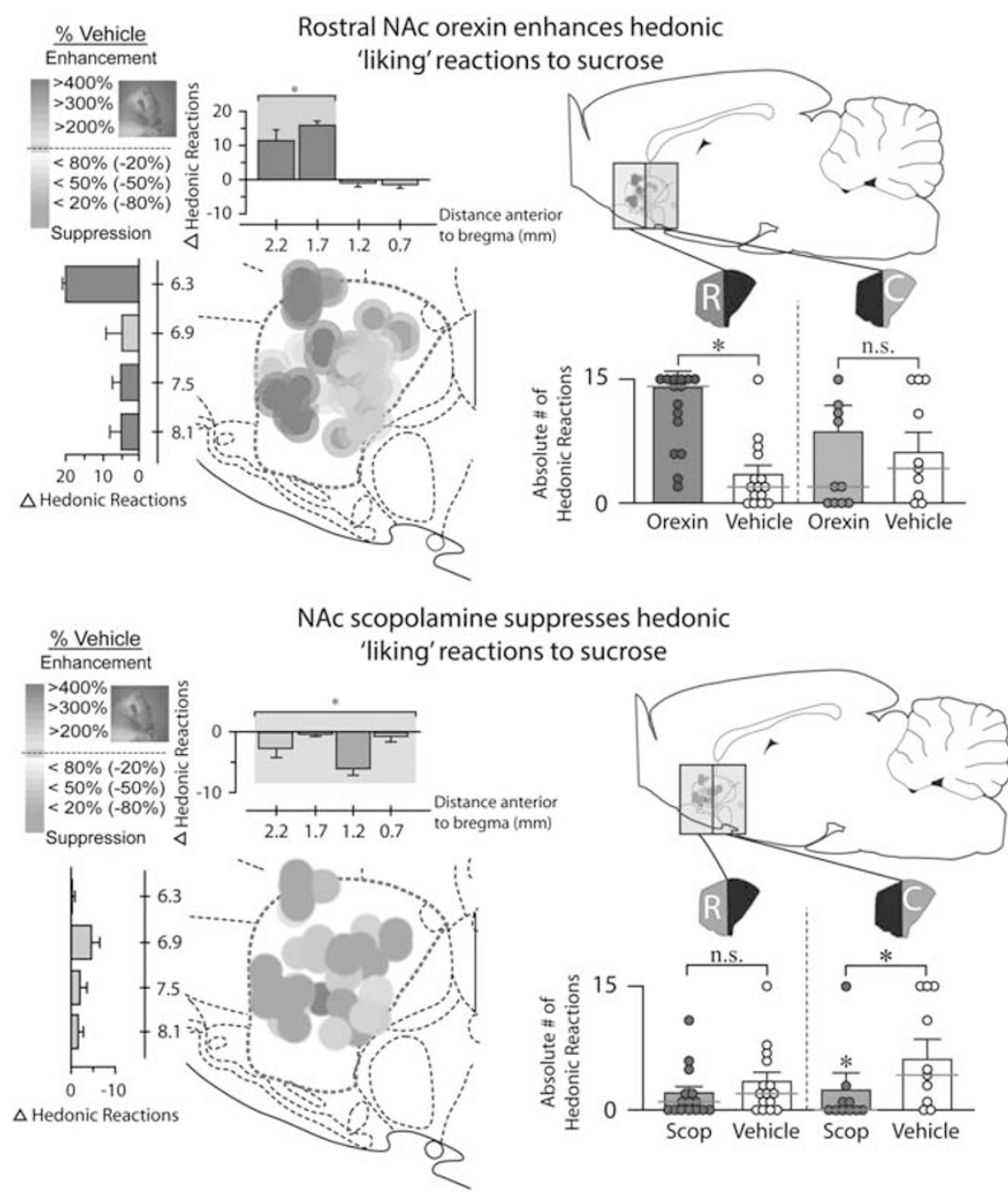

Figure 2 Orexin and scopolamine oppositely modulate hedonic reactions to sucrose. Sagittal causation maps for localization of function in NAc medial shell, showing changes in orofacial hedonic (liking) reactions elicited by sucrose taste after microinjections of either orexin or scopolamine (bottom; both compared with vehicle microinjection tests in the same rat). Each symbol placement indicates a microinjection site, the symbol size reflects the size of Fos plumes produced by that drug, and symbol color reflects the behavioral effects of the drug microinjection, shown as percentage change from vehicle control levels (enhancements: yellow-orange-red; suppressions: blue). Bars above and to the left of sagittal maps show mean absolute change in number of orofacial reactions induced by drug microinjection at that anterior-posterior or dorsal-ventral level. Total numbers of hedonic reactions are depicted in the bars graphs to the right of the sagittal maps, showing means with SEMs as bars (median as pink line), and individual data points as scatterplot circles. A full color version of this figure is available at the Neuropsychopharmacology journal online.

which were already nearly zero after vehicle microinjections, remained near zero and unchanged after scopolamine microinjections $\left(\chi^{2}=2.8, p=0.247\right)$.

\section{Scopolamine Suppresses Food Intake}

Scopolamine microinjections throughout medial shell similarly caused a $50 \%$ suppression of intake of palatable $M \& M$ chocolate candies $\left(\chi^{2}=30.333, p=0.0000001 ; Z=3.760\right.$, $p=0.00017 ; r=0.53 ; 95.7 \%$ CI $(-2.9,-2.5))$. This intake suppression did not differ between rostral and caudal sites (Figure 3) $\left(\chi^{2}=1.632, p=0.201\right)$, again consistent with previous reports of intake suppression at various NAc sites by Pratt and Kelley (2005). ACh blockade also decreased time spent drinking water $\left(\chi^{2}=12.194, p=0.002 ; Z=2.898\right.$, $p=0.004)$ and time spent rearing $\left(\chi^{2}=11.810, p=0.003\right.$; $Z=3.00, p=0.003$ ).

\section{Scopolamine Increases Fearful/Defensive Treading}

Scopolamine microinjections, especially in the caudal half of medial shell, also caused a fivefold increase in emission of defensive treading compared with vehicle days $\left(\chi^{2}=12.194\right.$, $p=0.002 ; Z=2.898, p=0.004 ; r=0.41 ; 95.7 \%$ CI $(0,20))$ (Figure 4). Defensive treading was elicited more intensely at microinjection sites in the caudal half of shell than in the rostral half of shell $\left(\chi^{2}=4.963, p=0.026\right.$; Rostral: $Z=1.718$, $p=0.086$; Caudal: $Z=2.293, p=0.022$ ). Defensive treading or burying is a natural anti-predator response of rodents, which is used to throw debris forward toward a localized threat, sometimes actually burying the object (ie, rattlesnake or shock prod) (Coss and Owings, 1978; Reynolds and Berridge, 2001,2008; Treit et al, 1981). Defensive treading was not emitted randomly within the chamber (indicating it was not simply a motor reaction), but rather was directionally 

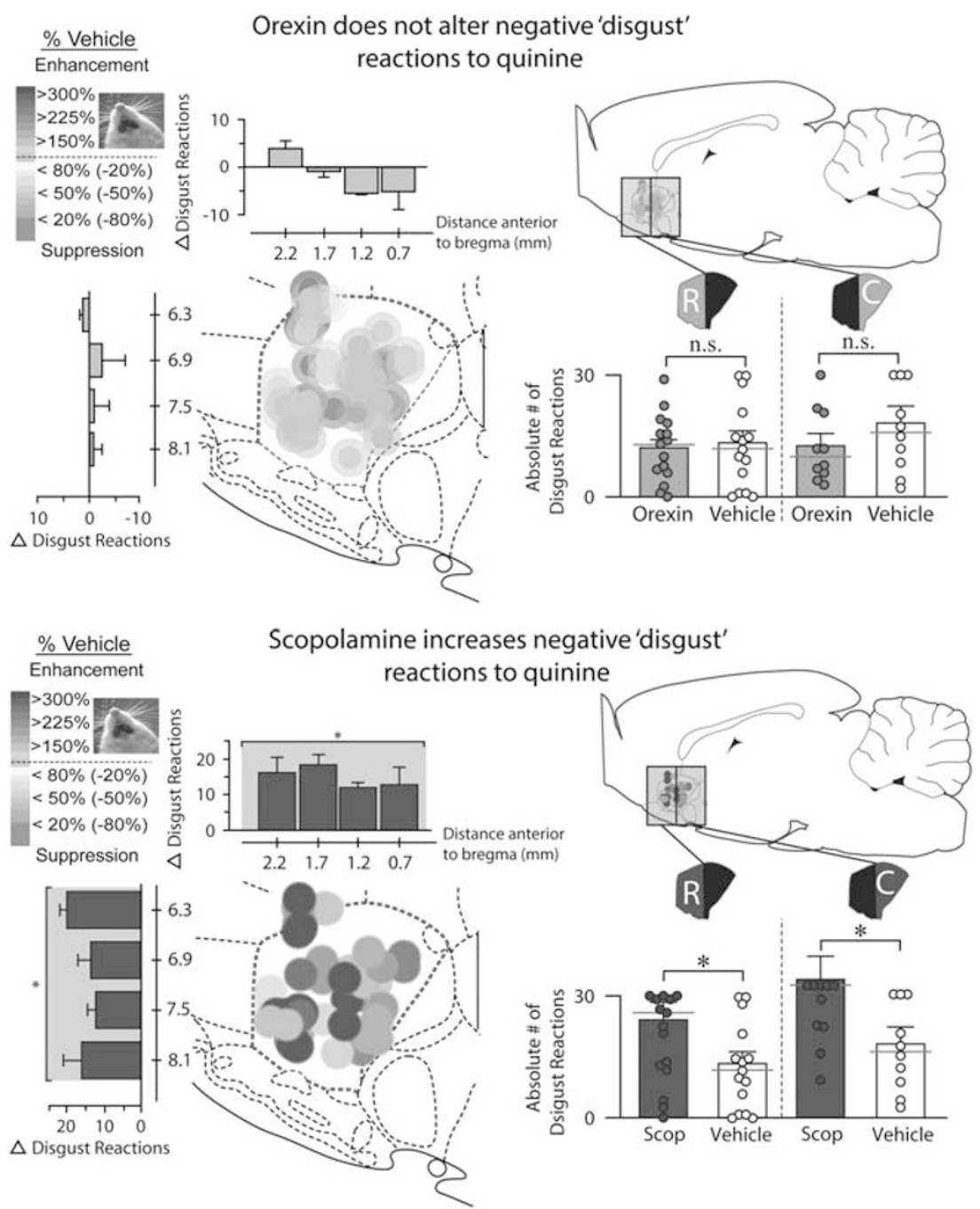

Figure 3 Scopolamine increases aversive 'disgust' reactions to bitter quinine. Sagittal maps showing changes in aversive (disgust) orofacial reactions to bitter quinine taste after microinjections of orexin or scopolamine (bottom). Maps and symbols as in Figure 2, but with increases in 'disgust' reactions reflected by shades of purple. A full color version of this figure is available at the Neuropsychopharmacology journal online.

focused toward the four corners of the transparent plastic chambers, which may have reflected light in a slightly glittering fashion.

\section{Potential Independence of Changes in Taste Reactivity, Food Intake, and Defensive Treading}

Food intake and 'liking' reaction enhancement by orexin microinjections in the NAc rostral shell hotspot were not highly correlated (Spearman's $R ; \mathrm{I}=-0.148, p=0.598$, $\left.R^{2}=0.0219\right)$. That appeared to be because orexin microinjections produced roughly $250 \%$ increases in sucrose-elicited 'liking' reactions, regardless of whether the intake increase was small (110-149\% of vehicle levels) or large ( $>150 \%)$. Although scopolamine microinjections in NAc shell tended to suppress sucrose 'liking' reactions, increase bitterness 'disgust' reactions, suppress food intake, and in caudal shell increase defensive treading, there was not a close statistical association among these effects. Similarly, the degree of scopolamine suppression of food intake was not correlated to the degree of suppression of hedonic reactions to sucrose or enhancement of quinine aversion (sucrose suppression: $\rho=-0.027, \quad p=0.90, \quad R^{2}=0.05 ;$ quinine enhancement: $\left.\rho=0.224, p=0.293, R^{2}=0.014\right)$. Finally, the increase in fearful/defensive treading caused by scopolamine microinjections was also statistically independent of the increase in 'disgust' reactions to quinine caused by those same microinjections $\left(\rho=0.137, p=0.0 .672, R^{2}=0.019\right)$. However, since taste reactivity and intake/treading behaviors were tested at different times after microinjections, their temporal separation might have promoted a degree of uncoupling. For sites outside the hotspot, orexin-induced increases in intake were not accompanied by any hedonic enhancement, making the stimulation of eating even more independent.

The hedonic suppression caused by scopolamine microinjections also was not tightly correlated to the elevation of quinine 'disgust' reactions ( $\rho=-0.174, p=0.417, R^{2}=0.03$ ). This result appears to be because scopolamine microinjections roughly doubled the number of quinine 'disgust' reactions regardless of whether it only slightly reduced sucrose 'liking' reactions ( $25 \%$ reduction; ie, $75 \%$ of vehicle levels) or produced a greater hedonic suppression. 


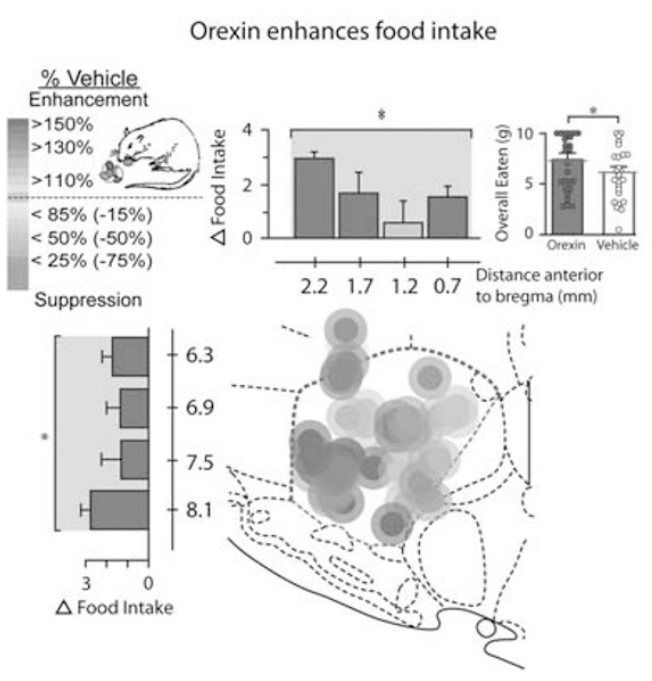

Scopolamine suppresses food intake

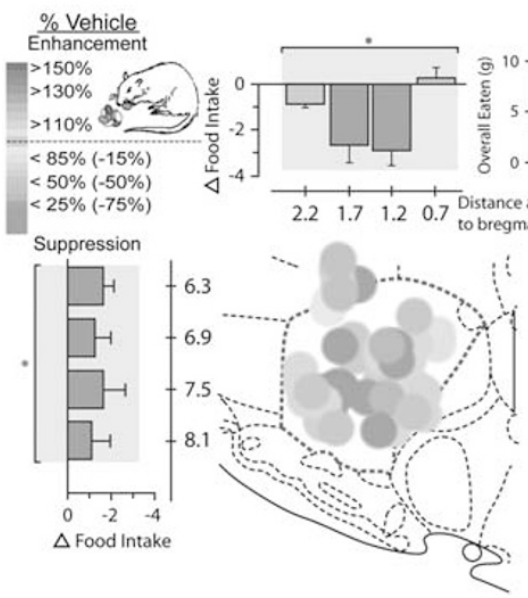

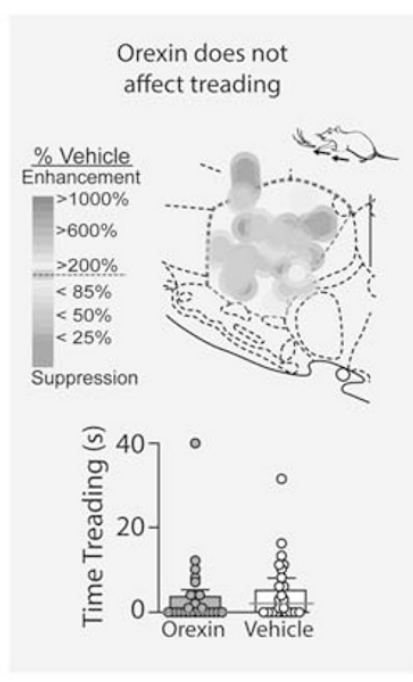

Scopolamine increases defensive treading
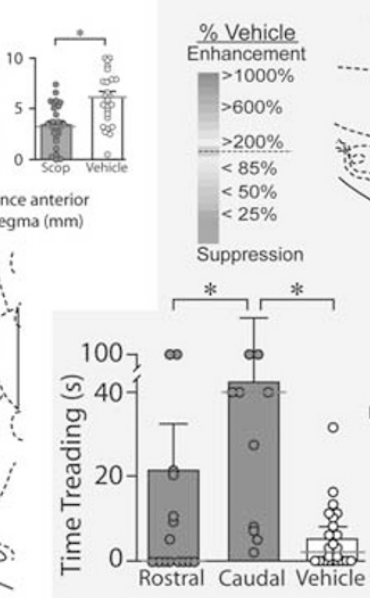

Figure 4 Orexin and scopolamine oppositely affect food intake. Sagittal causation maps for changes in food intake (palatable chocolate M\&M candies) and treading after either orexin (top) or scopolamine (bottom) microinjections. Intake effects are displayed as percentage changes from vehicle levels (enhancements: green; suppressions: blue) and treading effects are displayed as percentage changes from vehicle levels (enhancements: red; suppressions: blue). Maps and symbols otherwise as in Figure 2. The bottom-right panel displays the amount of time spent treading at each comer of the chamber. Location of experimenter and video camera designate the front of the chamber. A full color version of this figure is available at the Neuropsychopharmacology journal online.

\section{DISCUSSION}

\section{Overview}

Microinjections of orexin-A in the rostral half of NAc medial shell caused a $300 \%$ increase in the number of positive orofacial 'liking' reactions elicited by sucrose taste, whereas sites in the caudal half of shell failed to increase sucrose 'liking', revealing an anatomical orexin hotspot for hedonic enhancement. This hedonic hotspot was anatomically similar to the opioid hotspot in rostral shell previously mapped for mu-, delta-, and kappa-opioid stimulations (and overlapped with an endocannabinoid hedonic hotspot in dorsal shell previously mapped for anandamide enhancements (Castro and Berridge, 2014; Mahler et al, 2007)). However, unlike opioid stimulation in NAc, orexin stimulation never suppressed 'liking' reactions at posterior sites in the caudal half of medial shell, which were merely hedonically silent. By contrast, the motivation to eat, expressed as higher food consumption, was increased by orexin at all sites throughout the entire medial shell. Widespread anatomical NAc stimulation of intake is also similar to mu-opioid stimulation, which increases eating at all sites throughout shell and core, as well as in dorsal and ventrolateral regions of neostriatum, in central nucleus of amygdala, and in medial prefrontal cortex (Castro and Berridge, 2014; DiFeliceantonio et al, 2012; Mahler and Berridge, 2009; Mena et al, 2011; Pecina and Berridge, 2005; Ragnauth et al, 2000; Richard et al, 2013; Thorpe and Kotz, 2005; Zhang and Kelley, 2000).

Regarding $\mathrm{ACh}$ in hedonic impact and motivation, scopolamine blockade of NAc ACh muscarinic receptors typically suppressed both sucrose 'liking' reactions to below $50 \%$ normal levels and reduced palatable food intake to 
$50-70 \%$ of normal levels at most sites throughout medial shell. Scopolamine microinjections throughout nearly the entire NAc medial shell also doubled the number of 'disgust' reactions elicited by bitter quinine. However, scopolamine's induction of negative affect was never strong enough to actually create 'disgust' reactions to the sweet taste of sucrose (unlike GABA stimulations in caudal shell, which can reverse sucrose reactions from 'liking' to 'disgust' (Faure et al, 2010; Ho and Berridge, 2014; Reynolds and Berridge, 2002)). Finally, ACh blockade by scopolamine specifically in the caudal half of medial shell additionally elicited fear-related defensive treading behavior, which was directed toward locations in the chamber that may have been perceived as more threatening than others (eg, light-reflecting corners). These results suggest that endogenous muscarinic ACh signals, when present, help maintain the overall positive hedonic impact of the taste of food, as well as amplifying the motivation to eat, and in the caudal shell also potentially exerting an anxiolytic action.

\section{Orexin Rostral Hotspot}

Why the rostral half of NAc medial shell contains an anatomical hotspot for orexin and opioid hedonic enhancements needs further explanation, but it is known that rostral shell has several unique anatomical features that differentiate it from caudal shell, and which could be relevant. For example, the NAc rostrodorsal quadrant of medial shell has distinct inputs from a region in infralimbic cortex and outputs to ventral pallidum and hypothalamus that are different from other medial shell quadrants (Thompson and Swanson, 2010), resulting in a closed-circuit corticolimbicthalamocortical loop that runs parallel to loops passing through other regions of NAc shell. In addition, the rostral half of shell also has septal-like anatomical features that distinguish it from the extended amygdala-like features of caudal shell (Thompson and Swanson, 2010; Zahm et al, 2013). Neurons in rostrodorsal medial shell also have distinct morphological features, such as fewer spiny dendrites and smaller medium spiny neuronal cell bodies than other areas of NAc (Meredith et al, 2008; Zahm et al, 2013).

Neurochemically, the cellular mechanism for orexin enhancement of sucrose 'liking' also remains unclear. Orexin is typically thought to have excitatory depolarization effects on neurons (Korotkova et al, 2003; Marcus et al, 2001; Sakurai et al, 1998; Trivedi et al, 1998; van den Pol et al, 2002; Zhu et al, 2003). However, neurons in NAc may exclusively contain orexin-2 receptors $\left(\mathrm{OX}_{\mathrm{r}} 2\right)$ (Ch'ng and Lawrence, 2015; Trivedi et al, 1998), which can be coupled with either $\mathrm{Gi}$ or $\mathrm{Gq}$ subunits, and may inhibit neurons via the augmentation of inhibitory GABA signals (Martin et al, 2002; Zhu et al, 2003). If so, neuronal inhibition by orexin could be more similar to GABAergic hyperpolarizations or Gi-coupled opioid or endocannabinoid signaling. Future work could clarify the role of NAc neuronal inhibition $v s$ excitation for hedonic enhancement.

\section{Scopolamine Causes a Shift Toward Negative Affect and Motivation}

The ability of scopolamine microinjections throughout medial shell to suppress hedonic reactions to sucrose, increase aversive 'disgust' reactions to bitter quinine, and suppress intake of palatable food is consistent with the hypothesis by Kelley et al (2005) that endogenous ACh signals in NAc shell promote food intake (potentially by enhancing palatability). Their ACh-appetite hypothesis arose from the original demonstrations that scopolamine microinjections into NAc suppressed food intake, and that NAc scopolamine microinjections also could serve as an unconditioned stimulus to induce conditioned avoidance of either a paired taste or a paired place (Pratt and Kelley, 2004; Pratt et al, 2007). ACh also appears to interact with mu-opioid signals in NAc shell, as indicated by reports that NAc scopolamine reduces preproenkephalin mRNA levels, and blocks the ability of mu-opioid agonist microinjection in NAc to stimulate eating (Perry et al, 2014; Pratt and Kelley, 2005). A role for NAc ACh in incentive motivation and reward also seems consistent with reports that spontaneous firing in NAc neurons (including $\mathrm{ACh}$ interneurons) is evoked by reward events (Morris et al, 2004), interactions between insulin and ACh interneurons can directly modulate dopamine release in response to food rewards (Stouffer et al, 2015), and that optogenetic inhibition of ACh interneurons in NAc prevents the establishment of a cocaine conditioned place preference (Witten et al, 2010).

\section{CONCLUSION}

These results reveal an anatomically localized hedonic hotspot in NAc rostral half of medial shell for orexin enhancement of sweetness 'liking', but more distributed orexin mechanisms in NAc shell for stimulating motivation or 'wanting' to eat palatable food. They also support a positive role for endogenous NAc ACh signals in both hedonic impact and appetitive motivation. Collectively, these data help elucidate how orexin and ACh neurochemical signals in NAc contribute to sensory hedonic impact and the motivation to eat.

\section{FUNDING AND DISCLOSURE}

The enclosed manuscript contains original research that has not been published. These studies were supported by NIH grants MH63649 and DA015188 to KCB, and DCC was supported by NIH training grant DC00011. The authors declare no conflict of interest.

\section{ACKNOWLEDGMENTS}

We thank Cristina Muñoz, Cody Schember, and Josh Goldman for their help with immunohistochemistry.

\section{REFERENCES}

Avena NM, Rada P, Hoebel BG (2008). Underweight rats have enhanced dopamine release and blunted acetylcholine response in the nucleus accumbens while bingeing on sucrose. Neuroscience 156: $865-871$.

Baldo BA, Daniel RA, Berridge CW, Kelley AE (2003). Overlapping distributions of orexin/hypocretin- and dopamine-beta-hydroxylase immunoreactive fibers in rat brain regions mediating arousal, motivation, and stress. J Comp Neurol 464: 220-237. 
Barson JR, Ho HT, Leibowitz SF (2015). Anterior thalamic paraventricular nucleus is involved in intermittent access ethanol drinking: role of orexin receptor 2. Addict Biol 20: 469-481.

Berridge KC (2000). Measuring hedonic impact in animals and infants: microstructure of affective taste reactivity patterns. Neurosci Biobehav Rev 24: 173-198.

Berridge KC, Kringelbach ML (2015). Pleasure systems in the brain. Neuron 86: 646-664.

Berthoud HR, Munzberg H (2011). The lateral hypothalamus as integrator of metabolic and environmental needs: from electrical self-stimulation to opto-genetics. Physiol Behav 104: 29-39.

Castro DC, Berridge KC (2014). Opioid hedonic hotspot in nucleus accumbens shell: mu, delta, and kappa maps for enhancement of sweetness 'liking' and 'wanting'. J Neurosci 34: 4239-4250.

Ch'ng SS, Lawrence AJ (2015). Distribution of the orexin-1 receptor (OX1R) in the mouse forebrain and rostral brainstem: a characterisation of OX1R-eGFP mice. J Chem Neuroanat 66-67: $1-9$.

Clarke SN, Ossenkopp KP (1998). Taste reactivity responses in rats: influence of sex and the estrous cycle. Am J Physiol 274: R718-R724.

Coss RG, Owings DH (1978). Snake-directed behavior by snake naive and experienced California ground squirrels in a simulated burrow. Z Tierpsychol 48: 421-435.

Covelo IR, Patel ZI, Luviano JA, Stratford TR, Wirtshafter D (2014). Manipulation of GABA in the ventral pallidum, but not the nucleus accumbens, induces intense, preferential, fat consumption in rats. Behav Brain Res 270: 316-325.

DiFeliceantonio AG, Mabrouk OS, Kennedy RT, Berridge KC (2012). Enkephalin surges in dorsal neostriatum as a signal to eat. Curr Biol 22: 1918-1924.

Espana RA, Valentino RJ, Berridge CW (2003). Fos immunoreactivity in hypocretin-synthesizing and hypocretin-1 receptorexpressing neurons: effects of diurnal and nocturnal spontaneous waking, stress and hypocretin-1 administration. Neuroscience 121: 201-217.

Faure A, Richard JM, Berridge KC (2010). Desire and dread from the nucleus accumbens: cortical glutamate and subcortical GABA differentially generate motivation and hedonic impact in the rat. PLoS One 5: e11223.

Flynn FW, Schulkin J, Havens M (1993). Sex differences in salt preference and taste reactivity in rats. Brain Res Bull 32: 91-95.

Grill HJ, Norgren R (1978). The taste reactivity test. I. Mimetic responses to gustatory stimuli in neurologically normal rats. Brain Res 143: 263-279.

Harris GC, Wimmer M, Aston-Jones G (2005). A role for lateral hypothalamic orexin neurons in reward seeking. Nature 437: 556-559.

Ho CY, Berridge KC (2013). An orexin hotspot in ventral pallidum amplifies hedonic 'liking' for sweetness. Neuropsychopharmacology 38: $1655-1664$.

Ho CY, Berridge KC (2014). Excessive disgust caused by brain lesions or temporary inactivations: mapping hotspots of the nucleus accumbens and ventral pallidum. Eur J Neurosci 40: 3556-3572.

Kelley AE, Baldo BA, Pratt WE (2005). A proposed hypothalamicthalamic-striatal axis for the integration of energy balance, arousal, and food reward. J Comp Neurol 493: 72-85.

Korotkova TM, Sergeeva OA, Eriksson KS, Haas HL, Brown RE (2003). Excitation of ventral tegmental area dopaminergic and nondopaminergic neurons by orexins/hypocretins. J Neurosci 23: 7-11.

Mahler SV, Berridge KC (2009). Which cue to 'want?' Central amygdala opioid activation enhances and focuses incentive salience on a prepotent reward cue. J Neurosci 29: 6500-6513.

Mahler SV, Smith KS, Berridge KC (2007). Endocannabinoid hedonic hotspot for sensory pleasure: anandamide in nucleus accumbens shell enhances 'liking' of a sweet reward. Neuropsychopharmacology 32: 2267-2278.

Maldonado-Irizarry CS, Swanson CJ, Kelley AE (1995). Glutamate receptors in the nucleus accumbens shell control feeding behavior via the lateral hypothalamus. J Neurosci 15: 6779-6788.

Marcus JN, Aschkenasi CJ, Lee CE, Chemelli RM, Saper CB, Yanagisawa $\mathrm{M}$ et al (2001). Differential expression of orexin receptors 1 and 2 in the rat brain. J Comp Neurol 435: 6-25.

Mark GP, Rada P, Pothos E, Hoebel BG (1992). Effects of feeding and drinking on acetylcholine release in the nucleus accumbens, striatum, and hippocampus of freely behaving rats. J Neurochem 58: 2269-2274.

Mark GP, Weinberg JB, Rada PV, Hoebel BG (1995). Extracellular acetylcholine is increased in the nucleus accumbens following the presentation of an aversively conditioned taste stimulus. Brain Res 688: 184-188.

Martin G, Fabre V, Siggins GR, de Lecea L (2002). Interaction of the hypocretins with neurotransmitters in the nucleus accumbens. Regul Pept 104: 111-117.

Mena JD, Sadeghian K, Baldo BA (2011). Induction of hyperphagia and carbohydrate intake by mu-opioid receptor stimulation in circumscribed regions of frontal cortex. J Neurosci 31: 3249-3260.

Meredith GE, Baldo BA, Andrezjewski ME, Kelley AE (2008). The structural basis for mapping behavior onto the ventral striatum and its subdivisions. Brain Struct Funct 213: 17-27.

Morris G, Arkadir D, Nevet A, Vaadia E, Bergman H (2004). Coincident but distinct messages of midbrain dopamine and striatal tonically active neurons. Neuron 43: 133-143.

Patyal R, Woo EY, Borgland SL (2012). Local hypocretin-1 modulates terminal dopamine concentration in the nucleus accumbens shell. Front Behav Neurosci 6: 82.

Paxinos G, Watson C (2007). The Rat Brain in Stereotaxic Coordinates. Academic: New York.

Pecina S, Berridge KC (2005). Hedonic hot spot in nucleus accumbens shell: where do mu-opioids cause increased hedonic impact of sweetness? J Neurosci 25: 11777-11786.

Pecina S, Berridge KC (2013). Dopamine or opioid stimulation of nucleus accumbens similarly amplify cue-triggered 'wanting' for reward: entire core and medial shell mapped as substrates for PIT enhancement. Eur J Neurosci 37: 1529-1540.

Perry ML, Baldo BA, Andrzejewski ME, Kelley AE (2009). Muscarinic receptor antagonism causes a functional alteration in nucleus accumbens mu-opiate-mediated feeding behavior. Behav Brain Res 197: 225-229.

Perry ML, Pratt WE, Baldo BA (2014). Overlapping striatal sites mediate scopolamine-induced feeding suppression and mu-opioid-mediated hyperphagia in the rat. Psychopharmacology (Berl) 231: 919-928.

Peyron C, Tighe DK, van den Pol AN, de Lecea L, Heller HC, Sutcliffe JG et al (1998). Neurons containing hypocretin (orexin) project to multiple neuronal systems. J Neurosci 18: 9996-10015.

Pratt WE, Kelley AE (2004). Nucleus accumbens acetylcholine regulates appetitive learning and motivation for food via activation of muscarinic receptors. Behav Neurosci 118: 730-739.

Pratt WE, Kelley AE (2005). Striatal muscarinic receptor antagonism reduces 24-h food intake in association with decreased preproenkephalin gene expression. Eur J Neurosci 22: 3229-3240.

Pratt WE, Spencer RC, Kelley AE (2007). Muscarinic receptor antagonism of the nucleus accumbens core causes avoidance to flavor and spatial cues. Behav Neurosci 121: 1215-1223.

Ragnauth A, Moroz M, Bodnar RJ (2000). Multiple opioid receptors mediate feeding elicited by $\mathrm{mu}$ and delta opioid receptor subtype agonists in the nucleus accumbens shell in rats. Brain Res 876: $76-87$.

Reynolds SM, Berridge KC (2001). Fear and feeding in the nucleus accumbens shell: rostrocaudal segregation of GABA-elicited defensive behavior versus eating behavior. J Neurosci 21: 3261-3270. 
Reynolds SM, Berridge KC (2002). Positive and negative motivation in nucleus accumbens shell: bivalent rostrocaudal gradients for GABA-elicited eating, taste 'liking'/'disliking' reactions, place preference/avoidance, and fear. J Neurosci 22: 7308-7320.

Reynolds SM, Berridge KC (2008). Emotional environments retune the valence of appetitive versus fearful functions in nucleus accumbens. Nat Neurosci 11: 423-425.

Richard JM, Castro DC, Difeliceantonio AG, Robinson MJ, Berridge KC (2013). Mapping brain circuits of reward and motivation: in the footsteps of Ann Kelley. Neurosci Biobehav Rev 37: 1919-1931.

Rolls A, Colas D, Adamantidis A, Carter M, Lanre-Amos T, Heller HC et al (2011). Optogenetic disruption of sleep continuity impairs memory consolidation. Proc Natl Acad Sci USA 108: 13305-13310.

Sakurai T, Amemiya A, Ishii M, Matsuzaki I, Chemelli RM, Tanaka $\mathrm{H}$ et al (1998). Orexins and orexin receptors: a family of hypothalamic neuropeptides and $\mathrm{G}$ protein-coupled receptors that regulate feeding behavior. Cell 92: 573-585.

Sharf R, Sarhan M, Brayton CE, Guarnieri DJ, Taylor JR, DiLeone RJ (2010). Orexin signaling via the orexin 1 receptor mediates operant responding for food reinforcement. Biol Psychiatry 67: 753-760.

Shinohara Y, Inui T, Yamamoto T, Shimura T (2009). Cannabinoid in the nucleus accumbens enhances the intake of palatable solution. Neuroreport 20: 1382-1385.

Smith KS, Berridge KC (2005). The ventral pallidum and hedonic reward: neurochemical maps of sucrose 'liking' and food intake. J Neurosci 25: 8637-8649.

Smith KS, Berridge KC, Aldridge JW (2011). Disentangling pleasure from incentive salience and learning signals in brain reward circuitry. Proc Natl Acad Sci USA 108: E255-E264.

Soria-Gomez E, Matias I, Rueda-Orozco PE, Cisneros M, Petrosino S, Navarro L et al (2007). Pharmacological enhancement of the endocannabinoid system in the nucleus accumbens shell stimulates food intake and increases c-Fos expression in the hypothalamus. Br J Pharmacol 151: 1109-1116.

Steiner JE (1973). The gustofacial response: observation on normal and anencephalic newborn infants. Symp Oral Sens Percept 4: 254-278.

Steiner JE, Glaser D, Hawilo ME, Berridge KC (2001). Comparative expression of hedonic impact: affective reactions to taste by human infants and other primates. Neurosci Biobehav Rev 25: 53-74.

Stouffer MA, Woods CA, Patel JC, Lee CR, Witkovsky P, Bao L et al (2015). Insulin enhances striatal dopamine release by activating cholinergic interneurons and thereby signals reward. Nat Commun 6: 8543.

Sutcliffe JG, de Lecea L (2002). The hypocretins: setting the arousal threshold. Nat Rev Neurosci 3: 339-349.

Sweet DC, Levine AS, Kotz CM (2004). Functional opioid pathways are necessary for hypocretin-1 (orexin-A)-induced feeding. Peptides 25: 307-314.

Thompson RH, Swanson LW (2010). Hypothesis-driven structural connectivity analysis supports network over hierarchical model of brain architecture. Proc Natl Acad Sci USA 107: 15235-15239.

Thorpe AJ, Kotz CM (2005). Orexin A in the nucleus accumbens stimulates feeding and locomotor activity. Brain Res 1050: 156-162.

Treit D, Pinel JP, Fibiger HC (1981). Conditioned defensive burying: a new paradigm for the study of anxiolytic agents. Pharmacol Biochem Behav 15: 619-626.

Trivedi P, Yu H, MacNeil DJ, Van der Ploeg LH, Guan XM (1998). Distribution of orexin receptor mRNA in the rat brain. FEBS Lett 438: 71-75.

van den Pol AN, Ghosh PK, Liu RJ, Li Y, Aghajanian GK, Gao XB (2002). Hypocretin (orexin) enhances neuron activity and cell synchrony in developing mouse GFP-expressing locus coeruleus. J Physiol 541: 169-185.

Witten IB, Lin SC, Brodsky M, Prakash R, Diester I, Anikeeva P et al (2010). Cholinergic interneurons control local circuit activity and cocaine conditioning. Science 330: 1677-1681.

Zahm DS, Parsley KP, Schwartz ZM, Cheng AY (2013). On lateral septum-like characteristics of outputs from the accumbal hedonic 'hotspot' of Pecina and Berridge with commentary on the transitional nature of basal forebrain 'boundaries'. J Comp Neurol 521: 50-68.

Zhang M, Kelley AE (2000). Enhanced intake of high-fat food following striatal mu-opioid stimulation: microinjection mapping and fos expression. Neuroscience 99: 267-277.

Zhu Y, Miwa Y, Yamanaka A, Yada T, Shibahara M, Abe Y et al (2003). Orexin receptor type-1 couples exclusively to pertussis toxin-insensitive G-proteins, while orexin receptor type- 2 couples to both pertussis toxin-sensitive and -insensitive G-proteins. J Pharmacol Sci 92: 259-266. 